\title{
Editorial: Non-conventional materials
}

\section{Khosrow Ghavami PhD}

Professor, Pontificia Universidade Catolica do Rio de Janeiro, Rio de Janeiro, Brazil

We live in rapidly changing times dominated by multinational business and publicity. Although there are sufficient materials to build houses for all the people on earth, due to official norms and regulations engineers and architects cannot use their local materials. Everyday buildings are pulled down to make space for high-rise buildings constructed mainly with reinforced concrete, contributing to the generation of pollution. Industries contribute to increasing mountains of undesirable waste, which by its sheer quantity can lead to a catastrophe - as happened in November 2015 in the town Mariana, Brazil. A dam of a reservoir containing mining refuse broke; villages were flooded, people lost their lives and $600 \mathrm{~km}$ of a river was destroyed and contaminated. Whatever we do, we should consciously choose materials and be aware of the consequences for the environment and safety not only of our generation but those to come.

Natural vegetable fibres - such as wheat straw, which has been used in Iran (Persia) for thousands of years as reinforcement for soils for construction - and other natural fibres have been used not only as reinforcement in soil composites but also to provide us with clothing, ropes and wrapping for all sorts of different purposes. With the invention of new industrial products and the greed of multinationals thinking only about their profits, the world is facing serious ecological problems. Nylon is a good example: following industry's lobbying of the US Congress, it came to replace hemp. Today we have, on the one hand, a scarcity of nonrenewable materials and, on the other hand, enormous amounts of industrial waste, which pose a real threat for our planet. Our civilisation has produced islands of plastic material floating in the ocean and plastic particles have found their way into rivers and oceans in the most remote regions on earth.

This themed issue is dedicated to the topic of non-conventional materials (NOCMAT) and comprises the following contributions.

The first paper, by Camarini et al., ${ }^{1}$ presents results of tests on the use of recycled gypsum wastes in plaster and an evaluation of properties with regards to calcination time and temperature. The results show that the recycled gypsum plaster is superior to commercial gypsum plaster.

In the second paper, Villalón et $a .^{2}$ report on tests of glass-fibre laminates compared to samples where coir and epoxy were added. Results showed that samples with coir fibres had an increase in the dynamic elastic modulus value of $150-171 \%$ compared to that of samples without natural fibre. Higher volumes of epoxy improved coir fibre adhesion, preventing delamination, although this lowered the dynamic elastic value. Tensile tests confirmed that 30\% epoxy addition increased the stiffness of glass/coir, lowering their dynamic and quasi-static Young's modulus.

Monteiro et al., ${ }^{3}$ investigate the Tururi palm fibre (Manicaria saccifera Gaertn.), found in a sac that protects fruits of the Amazon Ubuçu palm. Their objective was to determine tensile, weight and regain values of the fibres from these sacs and sac strips both in natura and after discoloration; additionally, they carried out microscopy on longitudinal and cross-sections and performed Fourier transform infrared spectroscopy. The test results showed that the Tururi fibres are compatible with other lignocellulose fibres. Recommendations are given with regards to Tururi's sustainable extraction and application in products and as a composite material.

In the fourth paper, Bilba et al. ${ }^{4}$ evaluate sugar cane bagasse, a by-product and renewable resource, as mineral replacement and as reinforcement in cementitious paste. When ordinary Portland cement is partly replaced by natural pozzolan and bagasse ashes, a ternary binder is obtained. The thermal and flexural properties of bagasse/cement composites are investigated after periods of curing and then compared to composite pastes produced with commercial cement and bagasse fibres. More relevant results are obtained in a curing chamber where composite pastes prepared with ternary matrix conduct less heat than commercial binder composites at $28 \mathrm{~d}$ and obtain higher bending strength at 28 and $90 \mathrm{~d}$, particularly with untreated bagasse ash.

The last paper, by Delijani and Dick, ${ }^{5}$ deals with research results of the evaluation of the bond strength between the oriented strand board (OSB) skins and the polyurethane (PUR) foam core of PUR structural insulated panels as a measure of service life and fabrication quality. Until now, such panels have been barred by regulatory bodies because of an uncertain service life. Pull-out tests were performed on panels which had been subjected to harsh environmental conditions. Only $2 \cdot 5 \%$ of tests showed partial de-bonding at the interface of OSB and foam; $77 \cdot 5 \%$ of the remaining samples suffered shear failure within the foam, indicating acceptable bond strength. The remaining 20\% failed within the OSB skin. 


\section{REFERENCES}

1. Camarini G, dos Santos Lima KD and Pinheiro SMM (2016) Investigation on gypsum plaster waste recycling: an eco-friendly material. Green Materials 3(4): 104-112, http://dx.doi.org/10.1680/jgrma.15.00016.

2. Villalón M, Salas-Zuñiga R, Reyes-Zamora U et al. (2016) Effect on dynamic, quasi-static elastic moduli of glass fiber laminates. Green Materials 3(4): 113-119, http://dx.doi.org/10. 1680/jgrma.15.00020.

3. Monteiro AS, Leonardi B, Savastano H Jr and Baruque-Ramos $J$ (2016) Tururi palm fibrous material (Manicaria saccifera
Gaertn.) characterization. Green Materials 3(4): 120-131, http://dx.doi.org/10.1680/jgrma.15.00024.

4. Arsène MA, Bilba K, Onésippe $C$ and Rodier L (2016) Thermal and flexural properties of bagasse/cement composites. Green Materials 3(4): 132-143, http://dx.doi.org/10.1680/ jgrma.15.00012.

5. Delijani F and Dick KJ (2016) Serviceability of foam core structural panels based on bond strength. Green Materials 3(4): 144-150, http://dx.doi.org/10.1680/jgrma. 15.00027 . 